\title{
PENERAPAN PENDIDIKAN SEKS (UNDERWEAR RULES) TERHADAP PENCEGAHAN KEKERASAN SEKSUAL PADA ANAK DAN ORANG TUA DI SD NEGERI 52 WELONGE KABUPATEN SOPPENG
}

\section{The Applying Of Sex Education (Underwear rules) to Prevent Sexual Violence For Children And Parents at Elementary School 52 Welonge, Soppeng Districts}

\author{
Sitti Nurbaya, Muhammad Qasim \\ STIKES Nani Hasanuddin Makassar \\ E-mail korespondensi, gasimqasim63@yahoo.co.id
}

\begin{abstract}
The chairman of the National Commission for Child Protection stated that Indonesia had entered a National emergency. The data (KPAl) in 2015, the category of children dealing with case law keeps the first cases sequence of sexual violence against children (rape, sexual abuse, sodomy / pedophilia) and so on as much as $18 \%$ or 193 cases. Based on the report of the Empowerment of Women and Children and the report from the POLRES Soppeng, the researcher obtained data on sexual violence in children and adolescents, which increased from the previous year. Sexual violence in 2015 was 8 cases while in 2016 there was 15 cases of children with sexual violence. The purpose of this study was to determine the effect of the application of sex education (underwear rules) on the prevention of sexual violence in children and parents in Public Elementary School 52 Welonge in Soppeng Regency. This research used a Quasi Experimental research design with a pre-post test design approach. This research was carried out at Public Elementary School 52 Welonge in Soppeng regency in July-September 2018. The population in this study were all the students of Public Elementary School 52 Welonge as many as 122 students in the 2016/2016 academic year based on the population, as many as 87 respondents were taken from students and 87 from parents. Data collection used questionnaire. Based on the results of statistical test there is the influence of sex education (underwear rules) on the prevention of sexual violence in children and parents, the result of child prevention $(p=0.002$, smaller than the value of $\alpha=0.05)$ and the result of prevention of parental values $(p=0.003$, smaller than the value of $\alpha=0.05)$. So it can be concluded that there is an effect of the application of sex education (underwear rules) on the prevention of sexual violence in children and parents in Public Elementary School Welonge 52 in Soppeng Regency.
\end{abstract}

Keywords: Children, Parents, Sexual Violence, Sex Education

\section{ABSTRAK}

Ketua Komnas Perlindungan Anak menyatakan bahwa Indonesia telah memasuki masa darurat Nasional data (KPAI) Tahun2015 ketegori anak berhadapan dengan hukum $(A B H)$ kasus yang menepati urutan pertama kasus kekerasan seksual pada anak (Pemerkosaan, pencabulan, sodomi/pedofilia) dan sebagainya sebanyak 18\% atau 193 kasus. Berdasarkan laporan Pemberdayaan Perempuan dan Anak dan laporan dari POLRES Soppeng dari laporan tersebut peneliti memperoleh data kekerasan seksual pada anak dan remaja mengalami peningkatan dari tahun sebelumnya. Kekerasan seksual pada tahun 2015 sebanyak 8 kasus sedangkan tahun 2016 tercatat sebanyak 15 kasus anak dengan kekerasan seksual. Tujuan penelitian ini untuk mengetahui pengaruh penerapan pendidikan seks (underwear rules) terhadap pencegahan kekerasan seksual pada anak dan orang tua di SD Negeri 52 Welonge Kabupaten Soppeng. Jenis penelitian ini menggunakan rancangan penelitian Quasy Experimen dengan pendekatan Pre-post test design.Penelitian ini akan dilaksanakan di SD Negeri 52 Welonge Kabupaten Soppeng pada bulan Mei-Juli tahun 2018. Populasi dalam penelitian semua Murid SD Negeri 52 Welonge sebanyak 122 murid pada tahun ajaran2016/2017 berdasarkan populasinya maka diambil sampel sebanyak 87 responden dari murid dan 87 dari orang tua murid. Pengumpulan data menggunakan kuesioner. Berdasarkan hasil uji statistik terdapat pengaruh pendidikan seks (underwear rules) terhadap pencegahan kekerasan seksual pada anak dan orang tua hasil pencegahan anak $(p=0,002$, lebih kecil dari nilai $\alpha=0,05)$ dan hasil pencegahan orang tua nilai $(p=0,003$, lebih kecil dari nilai $\alpha=0,05)$.Jadi dapat disimpulkan bahwa terdapat pengaruh penerapan pendidikan seks (underwear rules) terhadap pencegahan kekerasan seksual pada anak dan orang tua di SD Negeri 52 Welonge Kabupaten Soppeng.

Kata Kunci : Anak, Kekerasan Seksual, Orang Tua, Pendidkan Seks,

\section{PENDAHULUAN}

Anak merupakan aset bangsa yang merupakan generasi penerus yang memiliki cita-cita dan harapan kedepan untuk pembangunan bangsa. Oleh karena itu sudah sepatutnya bahwa anak-anak harus mendapatkan perlindungan orang tua, keluarga, masyarakat dan negara. Hak-hak anak saat ini diatur secara rapi dalam aturan perundang-undangan di Indonesia dalam bentuk perlindungan dari berbagai tindak kejahatan agar hak-haknya tidak dilanggar. Namun faktanya sampai saat ini permasalahan pada anak begitu banyak kasus-kasus kejahatan yang dialami oleh anak-anak sehingga menyebabkan kejiwaan anak 
terganggu dan tidak dapat melaksanakan kewajibannya dengan baik (Sitompul, 2015).

Masalah yang sering didapatkan pada anak adalah kekerasan seksual. Kekerasan seksual pada anak yakni pemaksaan, ancaman atau keterperdayaan seorang anak dalam aktivitas seksual. Aktivitas seksual tersebut meliputi melihat, meraba, penetrasi (tekanan), pencabulan dan pemerkosaan. Dampak kekerasan seksual pada anak dapat berupa fisik, psikologis, maupun sosial. Dampak secara fisik dapat berupa luka atau robek pada selaput dara. Dampak psikologi meliputi trauma mental, ketakutan, malu, kecemasan bahkan keinginan atau percobaan bunuh diri (Paramastri, 2010).

UNICEFT (2010) telah melakukan survey tindak kekerasan pada anak umur 18-24 tahun di Kenya dan menunjukkan bahwa kekerasan terhadap anak merupakan masalah yang serius. Tingkat kekerasan sebelum usia 18 seperti dilansir pada umur 18 sampai 24 tahun menyatakan (pengalamannya seumur hidup) menunjukkan bahwa korban kekerasan seksual selama masa kanak-kanak, dimana $32 \%$ dialami perempuan dan $18 \%$ dialami oleh laki-laki. Para pelaku yang paling umum dari kekerasan seksual adalah lelaki sang pacar korban atau mitra atau teman mereka untuk romantis sebanyak $47 \%$, dan $43 \%$ dilakukan oleh tetangga.

Selanjutnya tiga dari sepuluh perempuan $30 \%$ berumur 18-24 tahun melaporkan pernah mengalami tindak kekerasan seksual sebelum usia 18 tahun yaitu (seks secara fisik, dipaksa, ditekan) sampai hasilnya menjadi hamil (UNICEFT, 2010).

Di Indonesia data yang dikeluarkan oleh Komisi Perlindungan Anak Indonesiia (KPAI) diurut berdasarkan kategori anak berhadapan hukum $(\mathrm{ABH})$ mengalami peningkatan setiap tahunnya dimana tahun 2013 sebanyak 1.413 kasus, tahun 2014 sebanyak 1428, dan tahun 2015 menghalami peningkatan menjadi 2.208 kasus(KPAl, 2016)

Adapun data diperoleh dari Lembaga Perlindungan Anak Sulawesi Selatan didapatkan data kekerasan seksual mengalami peningkatan setiap tahunnya data tahun 2011 sebanyak 112 kasus kekerasan seksual, tahun 2012 sebanyak 124 kasus dan tahun 2013 sebanyak 143 kasus (Alam, 2014)

Sedangkan Laporan pada kasus kekerasan seksual pada tahun 2015 sebanyak 8 kasus sedangkan tahun 2016 tercatat sebanyak 15 kasus anak dengan kekerasan seksual.

Merujuk pada data dan fakta yang terjadi khsusnya di Kabupaten Soppeng tentu pemerintah dan lebih khususnya kepada keluarga atau orang tua betapa penting untuk menjaga dan melindungi anak merekadan mencegah terjadinya kejahatan seksual baik itu anak laki-laki maupun anak perempuan. Langkah perlindungan anak dari kejahatan seksual juga harus dilakukan dari dalam dalam artian orang tua harus menjadi tempat pencegahan dan perlindungan pertama anakanaknya.

Upaya pencegahan yang efektif adalah dengan terus konsisten melakukan pendidikan seks secara dini kepada anak maupun orang tua yaitu melalui program underwear rules, program ini dipelopori oleh organisasi perlindungan anak dan pencegahan kekerasan pada anak Ingris The National Society for the Prevention of Cruelty to Children (NSPCC). Program underwear rules ini memudahkan orangtua untuk membuka pembicaraan seks dengan anak agar anak dapat menjaga dirinya dari kejahatan seksual. Program Underwear rules ini mengharapkan anak dapat menjaga dirinya dari orang-orang yang berniat melakukan kejahatan seksual sehingga anak dapat melakukan pencegahan dan perlindungan terhadap dirinya. Tujuan penelitian untuk mengetahui apakah ada pengaruh pendidikan seks underwear rulesterhadap pencegahan tindak kekrasan seksual pada anak dan orang tua di SD Negeri 52 Welonge Kabupaten Soppeng.

\section{METODE}

\section{Desain, Waktu dan Tempat}

Penelitian yang digunakan adalah Quasy Experimen dengan pendekatan Pre-post test design. Penelitian ini dilaksanakan pada Tanggal 01 Mei - 31 Juli Tahun 2018. Dan bertempat di SD Negeri 52 Welonge Desa Laringgi Kecamatan Marioriawa Kabupaten Soppeng

\section{Jumlah dan Cara Pengambilan Subjek}

Populasi penelitian ini adalah Seluruh Murid SD Negeri 52 Welonge Tahun Ajaran 2016/2017 sebanyak 112. Berdasarkan populasinya maka dapat diambil sampel rumus sloving sebanyak 87 responden dari murid dan orang tua murid

\section{Jenis dan Cara Pengumpulan Data \\ Pengumpulan data dilakukan menggunakan kuesioner yang terdiri dari pertanyaan-pertanyaan dibuat sendiri oleh peneliti berdasarkan literatur yang diperoleh untuk mengetahui pencegahan kekerasan}


seksual sebelum dilakukan intervensi. Setelah dilakukan pengukuran, dilakukanlah intervensi kepada anak dan orang tua dengan memberikan Pendidikan Seks (underwear rules). Kemudian peneliti kembali mengukur pengetahuan anak dan orang tua tentang pencegahan kekerasan seksualmenggunakan kuesioner. Data primer diperoleh berdasarkan hasil jawaban responden atas pertanyaan dan pernyataan yang diberikan.

\section{Pengolahan dan Analisis Data}

Pengolaan dilakukan dengan Analisa data berupa analisa univariat yaitu data yang diperoleh dari masing-masing variabel dimasukkan ke dalam variabel frekuensi. Selanjutnya dilakukan analisa bivariat yaitu untuk mengetahui atau menguji pengaruh antara variabel independen dengan variabel dependen menggunakan uji $t$ berpasang jika memenuhi syarat dan uji Wilcoxon sebagai alternatif ketika tidak data tidak memenuhi syarat.

\section{HASIL}

Berdasarakan data univariat Responden berdasarkan jenis kelamin dimana jenis kelamin terbanyak yaitu jenis kelamin laki-laki sebanyak 48 responden (87,3\%). Berdasarkan umur dimana umur terbanyak yaitu umur 8 tahun sebanyak 21 responden $(24,1 \%)$ dan umur terendah yaitu umur 7 tahun sebanyak 5 responden $(5,7)$. Berdasarkan kelas responden dimana kelas terbanyak yaitu kelas 2 sebanyak 27 responden $(31,0 \%)$ dan kelas terendah yaitu kelas 6 sebanyak 10 responden (11,5\%). Serta berdasarkan tinggal bersama orang tua semua responden tinggal bersama orang tua yaitu 87 responden (100\%).

Data pencegahan anak sebelum dan setelah dilakukan pendidikan kesehatan, dimana pencegahan anak sebelum dilakukan pendidikan kesehatan baik sebanyak 65 responden $(74.7 \%)$ dan pencegahan anak sebelum dilakukan pendidikan kesehatan kurang sebanyak 22 responden (25.3\%). Sedangkan pencegahan anak sesudah dilakukan pendidikan kesehatan dimana pencegahan anak sesudah dilakukan pendidikan kesehatan baik sebanyak 81 responden (93.1\%) dan pencegahan anak sesudah dilakukan pendidikan kesehatan kurang sebanyak 6 responden (6.9\%).

Berdasarkan jenis kelamin orang tua responden, dimana jenis kelamin orang tua terbanyak yaitu jenis kelamin perempuan sebanyak 72 responden (82.8\%). Berdasarkan rentang umur orang tua responden, dimana rentang umur orang tua terbanyak yaitu umur 36-40 tahun sebanyak 29 responden (33,3\%) dan rentang umur orang tua terendah yaitu umur 41-45 tahun sebanyak 14 responden (16.1\%). Berdasarkan pendidikan orang tua responden, dimana pendidikan orang tua terbanyak yaitu SMA sebanyak 36 responden $(41.4 \%)$ dan pendidikan orang tua terendah yaitu Sarjana sebanyak 2 responden (2.3\%). Berdasarkan pekerjaan orang tua responden, dimana pekerjaan orang tua terbanyak yaitu IRT sebanyak 67 responden (77.0\%) dan pekerjaan orang tua terendah yaitu petani sebanyak 1 responden (1.1\%).

Berdasarkan pencegahan pre orang tua dan post orang tua, dimana pencegahan sebelum dilakukan pendidikan kesehatan orang tua baik sebanyak 77 responden (88.5\%) dan pencegahan orang tua kurang sebanyak 10 responden (11.5\%). Sedangkan pencegahan sesudah pendidikan kesehatan orang tua dimana pencegahan orang tua baik sebanyak 86 responden $(98.9 \%)$ dan pencegahan orang tua kurang sebanyak 1 responden (1.1\%)

Hasil bivariat didapatkan pengaruh pendidikan kesehatan terhadap pencegahan pre anak - pencegahan post anak dengan uji statistik Wilcoxon diperoleh nilai $\rho=0,002$ jika di bandingkan dengan nilai $\alpha=0,05$, maka $\rho<\alpha$. Hal tersebut menunjukkan bahwa terdapat pengaruh pendidikan seks (underwear rules) terhadap pencegahan kekerasan seksual pada anak di SDN 52 Welonge kabupaten Soppeng.

Didapatkan data pengaruh pendidikan kesehatan terhadap pencegahan kekerasan seksual tua dengan uji statistik Wilcoxon diperoleh nilai $\rho=0,003$ jika di bandingkan dengan nilai $\alpha=0,05$, maka $\rho<\alpha$. Hal tersebut menunjukkan bahwa terdapat pengaruh pendidikan seks (underwear rules) terhadap pencegahan kekerasan seksual pada anak di SDN 52 Welonge kabupaten Soppeng.

\section{PEMBAHASAN}

Dalam pembahasan ini akan diarahkan untuk mengetahui pengaruh penerapan pendidikan seks (underwear rules) terhadap pencegahan kekerasan seksual pada anak dan orang tua di SD Negeri 52 Welonge Kabupaten Soppeng .

Hasil analisis bivariat antara variabel pengaruh pendidikan seks (underwear rules) terhadap pencegahan kekerasan seksual pada anak di SDN 52 Welonge dengan uji statistik Wilcoxon diperoleh nilai $\rho=0,002$ jika di bandingkan dengan nilai $\alpha=0,05$, maka $\rho<\alpha$. 
Hal tersebut menunjukkan bahwa terdapat pengaruh pendidikan seks (underwear rules) terhadap pencegahan kekerasan seksual pada anak di SDN 52 Welonge kabupaten Soppeng.

Hal tersebut sejalan dengan penelitian Muthmainnah dalam hal ini upaya pencegahan kekerasan seksual pada anak sangat perlu melalui pendidikan seks yang dikemas dalam penyampaian sederhana contoh membekali anak dengan keterampilan social seperti asertif yang mana bgaian tersebut salah satunya terdapat di program underwear rules. Asertif dalam artian anak diharapkan menyatakan ketidak setujuan atau penolakan dengan tegas. Anak dilatih untuk berani berkata "tidak" untuk melindungi dirinya dengan baik (Mutmainnah, 2014).

Seperti penelitian dilaksanakan oleh Novitasari tentang pencegahan pelecehan seksual pada anak melalui materi tubuhku Pelaksanaan pembelajaran tema 1 subtema 2 tentang Tubuhku dilaksanakan guru dengan baik dan dapat dipahami oleh siswa. Materi tema 1 subtema 2 tentang Tubuhku, khususnya bagian tubuh yang boleh dan tidak boleh disentuh orang lain merupakan salah satu cara efektif untuk melakukan pencegahan pelecehan seksual. Dengan menunjukkan kepada anak akan pentingnya bagian tubuh tertentu yang hanya menjadi miliknya atau privasi dan tidak boleh dilihat dan disentuh oleh orang lain (Novitasari, 2018).

Anak harus mengetahui bagian tubuh tertentu yang hanya boleh dilihat dan disentuh oleh dirinya. Meskipun kita ketahui orang lain melakukannya dengan bercanda memegang tetapi anak harus tetap diajarkan untuk melawan atau melindungi dirinya bahwa bagian tubuh tertentu itu hanya miliknya. Dari hasil kuesioner sebelum dilakukan pendidikan kesehatan terdapat diantaranya anak yang menagggap biasa memperlihatkan bagian tubuh tertentunya dan terbiasa tidak memakai baju saat keluar kamar bahkan saat keluar dari rumah. Setelah dilakukan pemberian kesehatan siswa pada saat dilakukan post test dan saat dilakukan pengukuran ulang oleh peneliti tentang pencegahan kekerasan seksual sebanyak 93.\% anak dapat menjawab dengan benar. Hal tersebut terdapat pengaruh setelah dilakukan pendidikan kesehatan dibuktikan adanya peningkatan pengetahuan pencegahan anak dalam mencegaha kekerasan seksual setelah dilakukan pendidikan seks.

Hal tersebut dikarenakan pendidikan seks underwar rules mempunyai aturan cukup sederhana yang memudahkan anak cepat memahami aturan-aturan dalam mencegah kekerasan seksual. Dalam hal ini underwear rules menjelaskan pendidikan seks kepada anak di mana orang lain tidak bisa mencoba untuk melihtat bagian yang tidak boleh dilihat atau menyentuh mereka, bagaimana anak bereaksi atau merespon tidak suka atau berkata tidak ketika ada orang ingin menyentuhnya dan bagaimana untuk menceritakan atau meminta bantuan kepada orang dewasa yang ia anggap percaya (Justicia, 2016).

Namun masih terdapat 6 anak yang memiliki pengetahuan pencegahan yang kurang setelah dilakukan pendidikan kesehatan .hal tesebut dikarenakan saat dilakukan pendidikan kesehatan terdapat anak yang perhatiannya kurang fokus kepada pemateri dikarenakan hasil observasi lingkungan kelas khusnya jendela kelas terbuat dari kaca yang transparan sehingga konsentrasi anak teralihkan kepada lingkungan luar kelas .

Hasil pencegahan pada orang tua murid berdasarkan uji statistik Wilcoxon diperoleh nilai $\rho=0,003$ jika di bandingkan dengan nilai $\alpha$ $=0,05$, maka $\rho<\alpha$. Hal tersebut menunjukkan bahwa terdapat pengaruh pendidikan seks (underwear rules) terhadap pencegahan kekerasan seksual pada orang tua di SDN 52 Welonge kabupaten Sopppeng.

Hasil penelitian ini sejalan disampaikan Justicia (2016) yang mana meneliti program underwear rules untuk mencegah kekerasan seksual pada anak usia dini, dalam penelitiannya mengatakan bahwa underwear rules merupakan panduan orangtua bahkan juga pendidik dalam mengajarkan pendidikan seks pada anak. Program yang diberikan underwear rules ini memudahkan orangtua untuk membuka pembicaraan seks dengan anak agar anak dapat menjaga dirinya dari pelaku-pelaku kejahatan seksual underwear rules mengharapkan anak dapat menjaga dirinya dari orang-orang yang berniat buruk pada anak serta dapat melindungi dirinya dan menjaga kesehatan seksual agar anak tidak melakukan penyimpangan seksual.

Upaya pencegahan kekerasan seksual orang tua anak SD Negeri 52 Welonge sejalan yang dikatakan Paramastri (2010) yang meneliti pencegahan dini terhadap kekerasan seksual pada anak, dalam penelitiannya mengatakan orang tua penting membekali anaknya untuk berperilaku asertif berkaitan dengan masalah kekerasan seksual ini. Sebagai contoh, beberapa orang tua telah mengajarkan agar menunjukkan respon tidak suka, menolak jika ada lawan jenis yang menciumnya, atau meraba tempat-tempat yang tidak semestinya (Paramastri, 2010). 
Upaya yang dilakukan oleh orang tua sejalan dengan penelitian Prabosiwi dimana orang tua harus menjadi tempat perlindungan pertama anak. Orang tua harus waspada dan memberikan bekal berupa pendidikan seks yang cukup bagi anak terkait keselamatan seksual mereka. Pendidikan seksual dapat diberikan sedini mungkin melalui kata dan kalimat yang sederhana namun tepat dan tidak vulgar. Penggunaan istilah sebenarnya akan membantu anak dalam mengkomunikasikan kejahatan seksual yang mungkin ia alami. Komunikasi yang baik antara anak dengan orang tua juga dipercaya mampu melindungi anak dari kejahatan seksual, paling tidak anak tidak akan menutupi kejadian yang dialaminya (Prabosiwi, 2015).

Dari hasil penelitian peneliti berpendapat bahwa dalam pelaksanaan Underwear rules oleh orang tua kepada anaknya, peneliti melihat bahwa prinsip underwer rules kesehariannya sering diaplikasikan dalam kehidupan keluarga. Disamping itu penggunaan bahasa sederhana sehingga memudahkan orang tua menyampaikan kepada anak mereka dan melakukan pencegahan kepada anak dengan prinsip tersebut tanpa andanya rasa malu kepada anak mereka sehingga dalam penelitian ini penerapan underwear rules hampir seluruhnya disampaikan kepada anak dengan upaya meningkatkan etika dan kesopanan anak baik dalam hal berperilaku maupun dengan berpakaian dalam kehidupan sehari-harinya sehingga digunakan dalam mencegah tindak kekerasan seksual pada anak di SD Negeri 52 Welonge.

Upaya pencegahan orang tua anak dalam penelitian ini menekankna dengan pendidikan seks organ reproduksi seperti tidak boleh dipertontonkan organ reproduksi secara sembarangan. Menumbuhkan rasa malu kepada anak, misalnya ketika keluar dari kamar mandi hendaknya memakai pakaian atau handuk penutup. Selain itu, jika ada yang menyentuhnya segera laporkan kepada orang tua atau guru di sekolah. Anak boleh berteriak sekeras-kerasnya dalam hal untuk melindungi dirinya.

Hasil penelitian diperolah setelah dilakukan pendidikan seks (Underwear rules) terdapat satu orang tua yang pencegahannya masih bdalam kategori kurang hal tersbut dikarenakan responden atau orang tua jenis kelamin laki-laki dan latar belakang pendidikan sekolah dasar. Dalam pemberian pendidikan seks kepada anak, responden belum sepenuhnya menyampaikan terkait fungsi organ reproduksi kepada anaknya adapun didapatkan jawaban dari responden diantaranya masih ia mengatakan belum sepenuhnya mengetahui fungsi organ reproduksi, masih merasa malu ketika membicarakan hal pendidikan seks. Selain itu orang tua tersebut mengatakan anak masih usia dini belum saatnya membicarakan hal tersebut, dan diperoleh orang tua tyang pencegahan kurang kepada anaknya dikarenakan kondisi dalam keluarga sibuk melakukan aktifitas di luar rumah.

\section{KESIMPULAN}

Terdapat pengaruh penerapan pendidikan seks (underwear rules) terhadap pencegahan kekerasan seksual pada anak dan orang tua di SD Negeri 52 Welonge Kabupaten Soppeng.

\section{SARAN}

\section{Orang Tua}

Diharapkan kepada keluarga agar lebih meningkatkan lagi upaya-upaya pencegahan kekerasan seksual pada anak secara dini dan menyampaikan kepada anak dengan bahasa yang sederhana mudah dimengerti sesuai dengan usia anak.

\section{Kepada Pihak Sekolah}

Diharapkan kepada pihak sekolah agar meningkatkan pemberian pendidikan kesehatan pencegahan kekerasan seksual baik itu melalui mata pelajaran ataupun sosialisasi lainnya di luar pelajaran khusus sehingga anak lebih memhami cara pencegahan kekerasan seksual.

\section{Untuk Masyarakat}

Untuk masyarakat agar kiranya dapat berperan serta dalam mencegah kekerasan seksual melalui prinsip underwear rules pada anak dengan mengajarkan kepada anak tata cara bergaul, berpakaian yang sopan serta ikut mensosialisasikan pencegahan kekerasan seksual di lingkungan sekitar masyarakat.

\section{Ucapan Terima Kasih}

Penulis mengucapkan ucapan terima kasih yang sebesar-besarnya kepada:

1. Direktorat Jenderal Penguatan Riset dan Pengembangan Kementerian Riset, Teknologi, dan Perguruan Tinggi, atas pemberian hibah penelitian dosen pemula

2. Ketua STIKES Nani Hasanuddin Makassar atas ijinnya dalam melaksanakan tugas penelitian

3. Kepala Unit Penelitian dan Pengabdian 
Masyarakat STIKES Nani Hasanuddin yang telah memberikan dukungan sehingga terlaksananya penelitian tanpa hambatan

4. Kepala Sekolah SDN 52 Welonge Kabupaten Soppeng

5. Media Kesehatan Politeknik Kesehatan Makassar

6. Dan seluruh pihak yang turut membantu dalam pelaksanaan penelitian hibah penelitan dosen pemula ini yang tak sempat kami sebutkan satu persatu kami ucapkan banyak terima kasih

\section{DAFTAR PUSTAKA}

ALAM, S. 2014. Perlindungan Hukum Bagi Anak Korban Kekerasan Seksual. Studi Pada Lembaga Perlindungan Anak Sulawesi Selatan. Jurnal UNM Makassar 95-102.

JUSTICIA, R. 2016. Program Underwear Rules Untuk Mencegah Kekerasan Seksual Pada Anak Usia Dini. Jurnal Pendidikan Usia Dini, Volume 09, 217-232.

KPAI 2016. Komisi Perlindungan Anak Indonesia (Anak Berhadapan Dengan Hukum). Jakarta.

MUTMAINNAH 2014. Membekali Anak Dengan Melindungi Diri. Jurnal Pendidikan Anak, Volume III, 443-451.
NOVITASARI, I. I. 2018. Pencegahan Pelecehan Seksual Pada Anak Melalui Materi Tubuhku Di SD Muhammadiyah Pangkal pinang Publikasi Ilmiah.

PARAMASTRI, I. 2010. Early Prevention Toward sexual Abuse On Childern. Jurnal Psikologi, Volume 03, 1-12.

PRABOSIWI, R. 2015. Pedofilia Dan Kekerasan Seksual: Masalah Dan Perlindungan Terhadap Anak. Jurnal Sosio Informa, Volume 01, 29-40.

SITOMPUL, A. H. 2015. Kajian Hukum Tentang Tindak Kekerasan Seksual Terhadap Anak di Indonesia. Jurnal Lex Crimen, Volume IV, 46-56.

UNICEFT 2010. Violence Against Children In Kenya Findings From a 2010 National Survey. Republic Of Kenya. 


\section{LAMPIRAN}

Tabel 1. Distribusi Frekuensi Responden berdasarkan jenis kelamin, umur, kelas dan tinggal bersama responden di SDN 52 Welonge Kabupaten Soppeng

\begin{tabular}{ccc}
\hline Jenis Kelamin & $\mathbf{N}$ & $\mathbf{\%}$ \\
\hline Laki-Laki & 46 & 52,9 \\
Perempuan & 41 & 47,1 \\
Jumlah & 87 & 100 \\
\hline Umur & $\mathbf{N}$ & $\mathbf{\%}$ \\
\hline 7 Tahun & 5 & 5,7 \\
8 Tahun & 21 & 24,1 \\
9 Tahun & 16 & 18,4 \\
10 Tahun & 17 & 19,5 \\
11 Tahun & 18 & 20,7 \\
12 Tahun & 10 & 11,5 \\
Jumlah & 87 & 100 \\
\hline Kelas & $\mathbf{n}$ & $\mathbf{\%}$ \\
\hline Kelas 2 & 27 & 31,0 \\
Kelas 3 & 12 & 13,8 \\
Kelas 4 & 18 & 20,7 \\
Kelas 5 & 20 & 23,0 \\
Kelas 6 & 10 & 11,5 \\
Jumlah & 87 & 100 \\
\hline Tinggal Bersama & $\mathbf{n}$ & \% \\
Responden & & 100 \\
\hline Orang Tua & 87 & 100 \\
Jumlah & 87 &
\end{tabular}

Tabel 2. Distribusi Frekuensi Responden berdasarkan pencegahan anak sebelum dan setelah dilakukan pendidikan kesehatan prinsip (Underwear rules) di SDN 52 Welonge Kabupaten Soppeng

\begin{tabular}{|c|c|c|}
\hline \multicolumn{3}{|l|}{ Pre Anak } \\
\hline $\begin{array}{c}\text { Pencegahan Anak Sebelum } \\
\text { dilakukan Pendidikan Kesehatan }\end{array}$ & $\mathbf{n}$ & $\%$ \\
\hline Baik & 65 & 74,7 \\
\hline Kurang & 22 & 25,3 \\
\hline Jumlah & 87 & 100 \\
\hline \multicolumn{3}{|l|}{ Post anak } \\
\hline $\begin{array}{c}\text { Pencegahan Anak Sesudah } \\
\text { dilakukan Pendidikan Kesehatan }\end{array}$ & $\mathbf{n}$ & $\%$ \\
\hline Baik & 81 & 93,1 \\
\hline Kurang & 6 & 6,9 \\
\hline Jumlah & 87 & 100 \\
\hline
\end{tabular}


Tabel 3. Distribusi Frekuensi Responden berdasarkan jenis kelamin orang tua, umur orang tua, pendidikan orang tua dan Pekerjaan orang tua responden di SDN 52 Welonge Kabupaten Soppeng

\begin{tabular}{ccc}
\hline $\begin{array}{c}\text { Jenis Kelamin Orang } \\
\text { Tua }\end{array}$ & $\mathbf{n}$ & $\boldsymbol{\%}$ \\
\hline Laki-laki & 15 & 17,2 \\
Perempuan & 72 & 82,8 \\
Jumlah & 87 & 100 \\
\hline Umur Orang Tua & $\mathbf{n}$ & $\boldsymbol{\%}$ \\
\hline 27-30 Tahun & 21 & 24,1 \\
31-35 Tahun & 23 & 26,4 \\
36-40 Tahun & 29 & 33,3 \\
41-45 Tahun & 14 & 16,1 \\
Jumlah & 87 & 100 \\
\hline Pendidikan Orang Tua & $\mathbf{n}$ & $\boldsymbol{\%}$ \\
\hline SD & 14 & 16,1 \\
SMP & 35 & 40,2 \\
SMA & 36 & 41,4 \\
Sarjana & 2 & 2,3 \\
Jumlah & 87 & 100 \\
\hline Pekerjaan Orang Tua & $\mathbf{n}$ & $\boldsymbol{\%}$ \\
\hline IRT & 67 & 77,0 \\
Wiraswasta & 19 & 21,8 \\
Petani & 1 & 1,1 \\
Jumlah & 87 & 100 \\
\hline
\end{tabular}

Tabel 4. Distribusi Frekuensi Responden berdasarkan pencegahan anak sebelum dan setelah dilakukan pendidikan kesehatan prinsip (Underwear rules) di SDN 52 Welonge Kabupaten Soppeng

\begin{tabular}{ccc}
\hline \multicolumn{3}{c}{ Pre Orang Tua } \\
\hline Pre Orang Tua & $\mathbf{N}$ & $\mathbf{\%}$ \\
Baik & 77 & 88,5 \\
Kurang & 10 & 11,5 \\
Jumlah & 87 & 100 \\
\hline \multicolumn{4}{c}{ Post Orang Tua } & \\
\hline Post Orang Tua & $\mathbf{N}$ & $\mathbf{\%}$ \\
Baik & 86 & 98,9 \\
Kurang & 1 & 1,1 \\
Jumlah & 87 & 100 \\
\hline
\end{tabular}


Tabel 5. Hasil Analisis Bivariat Pengaruh pendidikan kesehatan terhadap pencegahan pre anak - pencegahan post anak

\begin{tabular}{ll}
\hline & $\begin{array}{l}\text { Pencegahan Pre Anak - } \\
\text { Pencegahan Post Anak }\end{array}$ \\
\hline$Z$ & $-3.138^{\mathrm{b}}$ \\
Asymp. Sig. (2-tailed) & .002 \\
\hline
\end{tabular}

Tabel 6. Hasil Analisis Bivariat Pengaruh pendidikan kesehatan terhadap Post Orang tuaPre Orang tua

\begin{tabular}{ll}
\hline & $\begin{array}{l}\text { Pencegahan Post Orang } \\
\text { tua -Pencegahan Pre } \\
\text { Orang Tua }\end{array}$ \\
\hline $\mathrm{Z}$ & $-3.000^{\mathrm{b}}$ \\
$\begin{array}{l}\text { Asymp. Sig. }(2- \\
\text { tailed) }\end{array}$ & .003 \\
\hline
\end{tabular}

